\title{
CONCEPTION OF PROVIDING THE OPERATIONAL DEVELOPMENT IN THE FUNCTIONING PROCESS OF INNOVATIVELY ORIENTED ENTERPRISES
}

\author{
Kateryna Boiarynova \\ Department of Management \\ National Technical University of Ukraine «Igor Sikorsky Kyiv Polytechnic Institute» \\ 37 Peremohy ave., Kyiv, Ukraine, 03056 \\ boyarinovaea@ukr.net
}

\begin{abstract}
Economic instability, continuous change of conditions, that innovatively oriented enterprises function in, complicate the achievement of planned results and decrease the efficiency of using strategic management of the development. Taking into account the aforesaid, the aim of the article is to elaborate a conception of providing the operational development in the functioning process of innovatively oriented enterprises, based on the complex of operational actions (economic functions), achieving tactic and strategic purpose-oriented results for transferring the economic system of an enterprise in the new development stage. According to research results, it was grounded, that the aim of functioning of innovatively oriented enterprises at realizing the operational development process forms as a combination of the innovatively oriented evolution of the economic system and the increase of the economic return for the further use in the development process. It was proved, that the development at the operational level is a process of purpose-oriented changes that provide transferring an enterprise to the new development stage. Such purpose-oriented changes are offered to be realized through realizing economic functions in the internal environment of an enterprise, directed not only on current functioning processes, but also development that allows to attain the sufficient economic return level. It was revealed, that it is expedient to realize them, based on using factors of production and management of economic relations both at the level "subject - object" and "object - object", considering an innovatively oriented enterprise as an ecosystem. For this aim, its construction and structure are grounded; the characteristic of key complicated functional environments of components of an ecosystem is given. It was elucidated, that the economic evolution of an enterprise takes place through the change of stages (phases) of the functional development level, at each of them the complex of economic functions is realized, and the economic return is obtained according to an achieved position in the development process.
\end{abstract}

Keywords: development, operational level, functioning, ecosystem, innovatively oriented enterprise.

\section{Introduction}

Scientific approaches to functioning of enterprises have formed for a long time, based on their life activity, considering this process as an economic activity that provides existence. Instead of it, the development of an enterprise was grounded on the methodology of strategic management. But economic instability, continuous change of conditions, that innovatively oriented enterprises function in, complicate the achievement of planned results and decrease the efficiency of using strategic management of the development. It conditions the growth of attention to managing the development that can be realized at the operational level and is provided by functioning processes.

Scientists conduct studies as to searching for ways of combining strategic management and operational measurement of productivity, revelation of interconnections of strategies with operational management [1], elaborate a model of integrated planning that includes not only strategic, but also project-oriented and operational planning with the strategic, tactic and operational feedback in the cybernetic outline of management of an enterprise [2]. Scientists investigate the flexibility of an enterprise at the operational level, because under conditions of continuous changes of the external environment, structure and management of all components of production systems, transformations must be realized fast and with minimal efforts [3] and ground operational management, oriented on a strategy, discover peculiarities of strategic, tactic and operational management of an industrial enterprise [4]. The proposed approach to realization of the conception of purpose-oriented management and also the model of management, formed of a series of "layers" are worth attention [4]:

1) systems of aims and parameters that is a kernel of the production-financial model of enterprises; 
2) systems of supporting making managerial decisions that includes functions of managing knowledge, imitative modeling, intellectual analysis of data;

3) processes of management and making decisions that are a part of the functional subsystem of an enterprise;

4) objects of the external environment, which behavior is expressed through the set of key parameters of an enterprise [4].

At the same time with the aforesaid, scientific studies actualize the question of managing the stable development both by realizing interconnected functions and based on the process of elaborating, making and realizing managerial decisions [5] in the functioning process of an enterprise.

But the complex approach to the operational development of an enterprise, that would be realized in the process of current activity and would provide achievement of tactic and strategic results for transferring the economic system in the new development phase, needs elaboration.

\section{Aim of research}

The aim of the research is to form a conception of providing the operational development in the process of functioning of innovatively oriented enterprises, based on the complex of operational actions (economic functions), achieving tactic and strategic purpose-oriented results for transferring the economic system of an enterprise in the new development stage.

\section{Materials and methods}

At the research there were used the abstract-logic method, method of logic generalizations and causal connection, ones of decomposition and systematization. The theoretical-methodological base of the research became scientific works of leading native and foreign scientists as to functioning of enterprises and operational management of their development.

\section{Results of research}

Functioning of innovatively oriented enterprises as dynamic economic systems is grounded just on economic-organizational principles, at which instruments of the innovatively oriented development are used. This peculiarity of functioning gain signs of not only the process of existence, life activity of an enterprise, but also its development. In such case the development of an enterprise may be considered as a change of the economic level of its functioning, based on actions, directed on achieving purpose orientations. At that innovations become instruments of the operational process of scientific-technical, technological and organizational changes. In this context the development of an innovatively oriented enterprise is the functioning process, directed on dynamic changes of elements of its internal environment that provides the economic evolution. At that the combination of functioning and development processes gain signs of the complex process of purpose-oriented changes that provides transferring an enterprise at the new development stage.

According to scientific works of classics, a firm must be oriented on the profit maximization, determined by a criterion of its development for the effective functioning [6]. Modern representatives of the entrepreneurial approach also consider profit as an aim of functioning of a firm [7]. But according to the entrepreneurial theory of a firm, there takes place the change of flows of physical resources for flows of knowledge and information, which improvement is provided by entrepreneurs by trust, cooperation and power influence $[8,9]$. In such case the aim of functioning of an enterprise, oriented on the development, is not simply gaining profit, but also experience and knowledge by realizing economic relations. Existence and functioning of a firm are provided by dynamic abilities, organizations must have a possibility to continuously recognize and use possibilities, periodically change organization aspects for realizing active changes for that [10]. That is at orienting on the development, an enterprise gains not only profit in the functioning process, but also dynamic abilities, knowledge, the economic and innovative level of its internal environment increases. In such case the aim of functioning of 
innovatively oriented enterprises at realizing the operational development process must form of two components: innovatively oriented evolution of the economic system, based on using knowledge, unique resources and abilities and increase of the economic return for the further use in the development process.

Observing the set aim, realization of functioning of innovatively oriented enterprises must include tactic and operational actions, directed on current processes of providing the development for attaining strategic aims (Fig. 1). At that development processes must be realized already at the operational level, gradually attaining tactic and strategic tasks. Realization of strategic tasks at the tactic level must be provided by two directions:

- Attaining the sufficient organizational and innovative level of the evolution of the economic system, based on self-development by realizing economic functions;

- Attaining the sufficient level of the economic return.

It forms the organizational-economic base for attaining strategic aims and transferring an innovatively oriented enterprise to the new development stage. Thus, under conditions of economic instability and variance of the external environment the development of an innovatively oriented enterprise must be realized already at the operational level at functioning processes.

The development as a property of dynamic economic systems that are innovatively oriented enterprises determines life activity as a continuous change of phases of functioning and development [11]. Conforming to the thought of scientists, the whole totality of functioning processes of an enterprise is divided in two groups: processes of manufacturing (and realization) of products and reproduction processes that function as simple and spread reproduction, the later include development processes of an enterprise [12]. In such case economic actions for providing a purpose-oriented result at each development stage must be realized through two complexes of functions:

1) functions, realized at functioning, namely provision ones, fixed for supplying an enterprise with economic abilities and economic resources, and reproduction ones, realized for recreating spent resources and potential;

2) functions that provide the development of an innovatively oriented enterprise, that is ones of spread reproduction, oriented on the qualitative and quantitative increase of resources, production factors and abilities and functions of innovative reproduction that provide the change of used production factors, resources and abilities for innovative ones, different from traditionally used, for providing functioning at the new quality level. Such distribution of spread reproduction in two components is conditioned by separating functions of innovative direction that provide not the economic growth, but just the development.

For realizing the development at the operational level, purpose orientations must be determined and purpose results of each separate function must be attained. Such orientation for an innovatively oriented enterprise must form of not only the innovative activity, but must take into account all economic activity directions. Together with the aforesaid the economic return influences the development of an innovatively oriented enterprise. At the low efficiency of realizing functions by an enterprise, the economic interest to it decreases, which results in its lowering. As a result, financial-economic resources for spread and innovative reproduction decrease, and the following functioning cycle is similar to the previous one and the development doesn't take place.

Realization of development processes at the operational level needs to change approaches to considering an enterprise as a structured system. Considering an innovatively oriented enterprise as an ecosystem (Fig. 2), its functional centers gain signs of functional environments at realizing economic functions. In such case the structure of an enterprise forms as an internal environment as an ecosystem with components of managerial, productive and financial-innovative activity, which the aforesaid environments are combined around. At that functions must be realized based on using factors of production and management of economic relations both at "subject - object" and "object - object" levels (Table 1). 


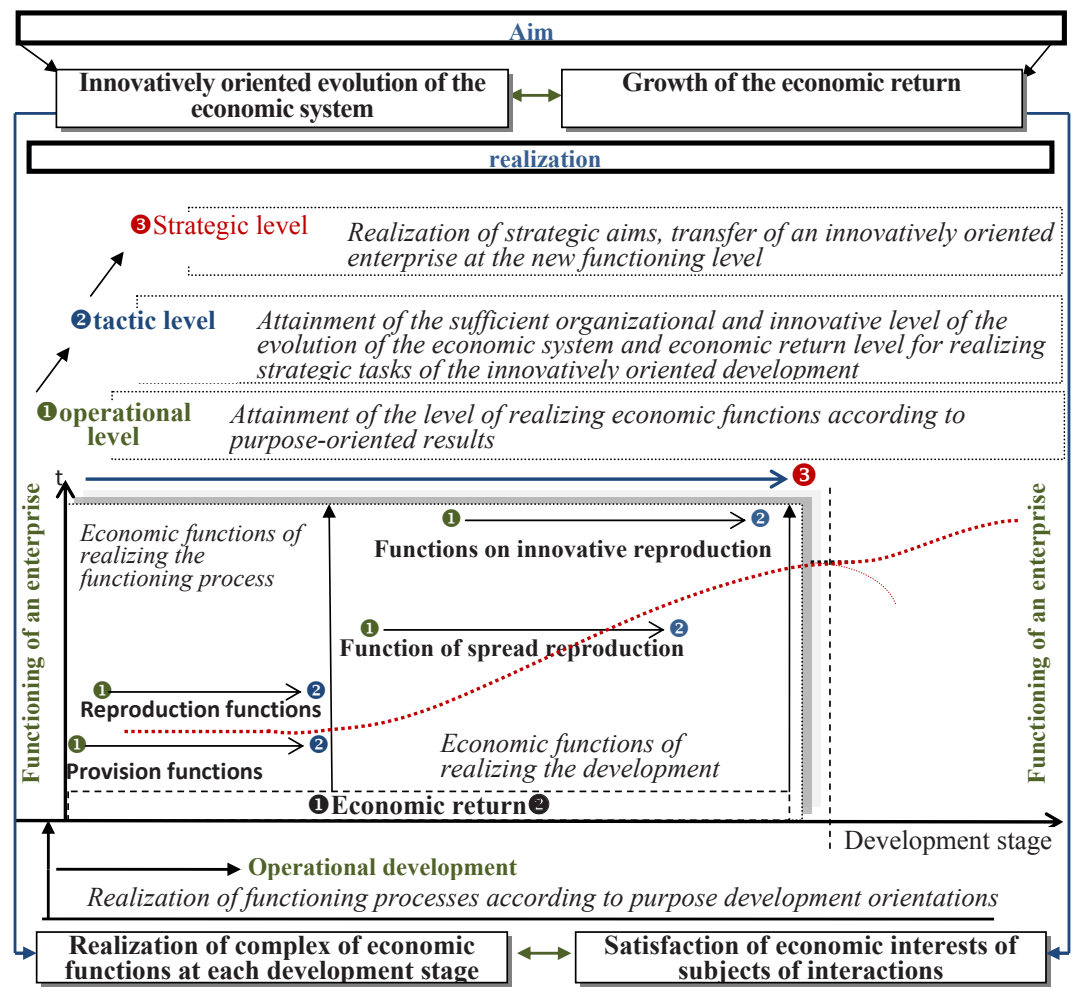

Fig. 1. Realization of economic functions in the development process of an innovatively oriented enterprise (elaborated by the author)

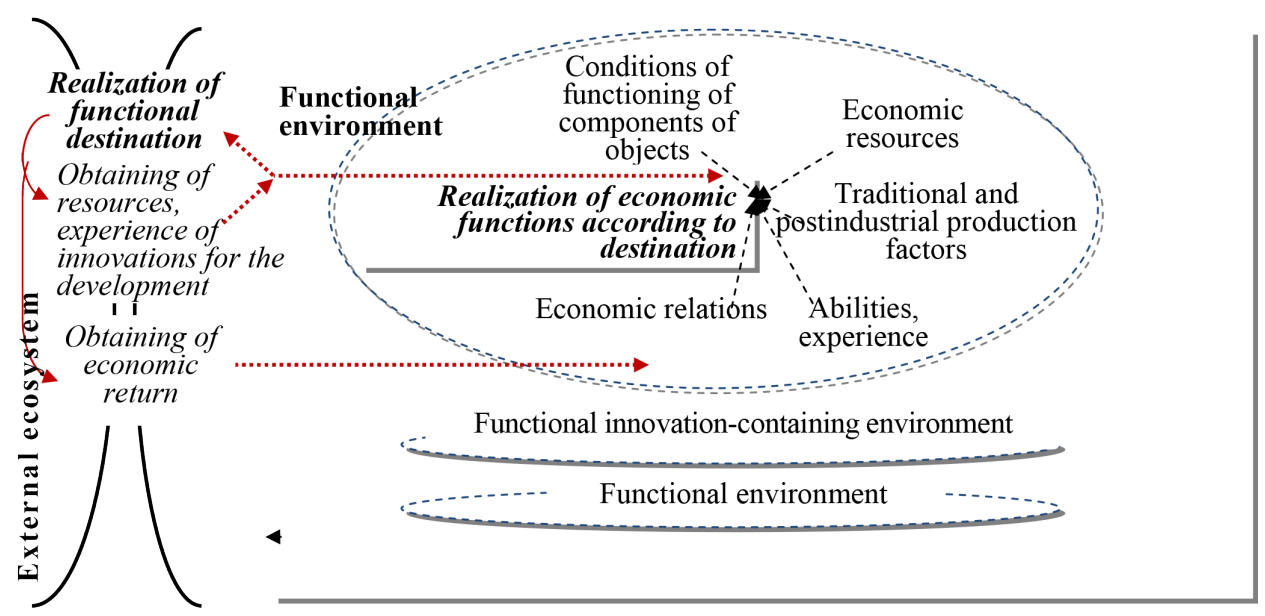

Fig. 2. Construction of the ecosystem of an innovatively oriented enterprise (elaborated by the author)

The development level of an innovatively oriented enterprise in the functioning process must be considered according to the coordinated position of production, managerial and financial-investment components of its ecosystem at the level of functional layers that correspond to realized functions (provision, reproduction, spread reproduction, innovative reproduction) and also in the position at the economic return level that allows to realize the complex of economic functions of the next functional level. Taking into account that the development of an enterprise takes place at transferring to the higher functioning level, the transfer from one level to another may be considered as a certain position of each functional component in the development stage. In such case the change of functional layers of the economic system from functioning to development gains signs of transferring to the following stage of the development functional level. That is the economic 
system at the operational development process transfers from stage (phasis) to stage, the complex of economic function is realized at each of them, and the economic return is obtained according to the achieved position in the development process.

\section{Table 1}

Characteristics of key elements of functional environments of components of the ecosystem of an innovatively oriented enterprise

\begin{tabular}{ccc}
\hline & Economic relations & Production factors \\
\hline 1 & 2 & 3 \\
\hline
\end{tabular}

Environment of operation of the industrial-production staff (realization of production by the staff)

At the level «subject - object»: management, qualification improvement, learning; «object - object»: salary, interaction with main means
Labor, capital, information, knowledge, intellect, potential, dynamic abilities

Environment of operation of financing of an enterprise (financing of production processes, renewal of main means, non-material assets)

At the level "subject - object": purchasing, distribution of finances, "object - object": circulation of capital at financing of production

Capital, mobilized involved finances

Environment of operation of production means (realization of the production process)

At the level "subject - object": interaction with the industrial-proe

Production component

duction staff, assembling, repair and setting up production; "object -

object" interaction with economic resources at production

\section{Innovative environment of operation of material assets (innovated production)}

At the level "subject - object": rationalization propositions, introduca tion of innovative equipment, correspondent to consumers' requirements; " object - object": interaction of material assets with staff's knowledge and innovative products

Innovative environment of operation of non-material assets (intellectualized production)

At the level "subject - object": interaction with the creative staff, developers and owners of right for objects of intellectual property; «object - object»: interaction of production means with the non-material component in the form of right for using intellectual property objects

\section{Environment of operation of the staff (influence on it)}

At the level "subject - object": interaction in the hierarchy of mane agement through motivation and labor organization; "object - object": Knowledge, intellect, innovative thinkinteraction of created conditions with staff's productivity, exchange of ing, potential, capital, dynamic abilities knowledge and experience

\section{Environment of business operation (business activity realization)}

At the level "subject - object": interaction with partners, suppliers, clients, state and local authorities, "object - object": interaction of

Managerial Component internal and external business-systems at getting incomes of products' relative (consumption) capital, economic realization

\section{Environment of operation of investment favoring (innovative and intellectual renovation)}

At the level "subject - object": interaction with design offices and other subjects of innovative infrastructure, stuff as to introducing innovations; "object - object": interaction of managerial technologies with objects of the production-economic system of an enterprise as innovatization and intellectualization
Knowledge, intellectual resources and capital, institution factors, intellect, innovative thinking, ownership, economic climate (together with innovative one) 


\begin{tabular}{|c|c|c|}
\hline 1 & 2 & 3 \\
\hline \multirow{6}{*}{$\begin{array}{l}\text { Financial-invest- } \\
\text { ment component }\end{array}$} & \multicolumn{2}{|c|}{$\begin{array}{c}\text { Environment of operation of internal financial-investment support (realization of the financial mechanism of } \\
\text { support) }\end{array}$} \\
\hline & $\begin{array}{l}\text { At the level "subject - object": management of distribution of } \\
\text { financial resources "object - object": interaction of own capital with } \\
\text { current processes of providing production-economic activity }\end{array}$ & Capital, dynamic abilities \\
\hline & \multicolumn{2}{|c|}{$\begin{array}{c}\text { Environment of operation of financial business-relations (realization of circulation of financial resources in } \\
\text { the business environment) }\end{array}$} \\
\hline & $\begin{array}{l}\text { At the level "subject - object": calculations with subjects of economic } \\
\text { relations; "object - object": interaction of money funds with results of } \\
\text { enterprise's activity }\end{array}$ & Capital, mobilized involved resources \\
\hline & \multicolumn{2}{|c|}{$\begin{array}{c}\text { Environment of operation of investment-partner relations (realization of financial investment-partner rela- } \\
\text { tions) }\end{array}$} \\
\hline & $\begin{array}{l}\text { At the level "subject - object": interaction with partners, creditors } \\
\text { and investors; "object - object": interaction of financial resources of } \\
\text { counter-agents, own and involved costs }\end{array}$ & $\begin{array}{l}\text { Capital, dynamic abilities, innovative } \\
\text { thinking, mobilized involved finances }\end{array}$ \\
\hline
\end{tabular}
debt dependence)

\footnotetext{
At the level "subject - object": paying off debts to creditors and investors; "object - object": interaction of own and reserve capital for providing stability
}

Capital, dynamic abilities

\section{Discussion}

Realization of the operational development of innovatively oriented enterprises is a complicated task that needs realization of systematic actions for attaining purpose results at tactic and strategic levels. Support of the evolution of the economic system needs to add functions that provide the development, to economic ones inherent to functioning. Such coordinated transfer to the new stage of the development functional level is not always achieved by enterprises and needs essential capital investments. In this connection purpose orientations of the development at the operational level must be set in the short-term perspective that allows to raise the reliability of taking into account factors of influence on achieving the effective activity of an enterprise. At that functions of spread and innovative reproduction, fixed for the development, must be realized taking into account the economic interest of subjects of economic relations that allows to attain the sufficient economic return level. It is expedient to realize these actions, based on using not only traditional production factors, but also postindustrial ones and also to manage economic relations at both "subject - object" and "object - object" level, considering the internal environment of an innovatively oriented enterprise as an ecosystem with functional centers of realization of both economic and innovative activity. So, the development of innovatively oriented enterprises under unstable economic functioning conditions must be realized at the operational level with gradually attaining tactic and strategic tasks through the evolution of the economic system for satisfying economic interests.

\section{Conclusions}

Thus, the conception of providing the operational development in the functioning process of innovatively oriented enterprises elucidates the methodological approach to realizing the development through realizing functions, using management of an enterprise as an economic ecosystem, and is grounded on the following principles:

1) development is realized in the functioning process, based on economic functions, fixed for realizing both current functional processes and development through spread and innovative reproduction of the economic system that provides the increase of economic interests to an enterprise and as a result - economic return; 
2) the aforesaid actions are realized based on using factors of production and management of economic relations both at the level "subject - object" and "object - object", considering an innovatively oriented enterprise as an ecosystem;

3 ) the effective realization of economic functions allows internal components of the ecosystem of an innovatively oriented enterprise to transfer at new development functional levels that provides attaining tactic aims and as a final result to realize strategic aims for transferring to the new development stage.

The proposed conception must be used at enterprises with the high innovation level of their economic activity. Taking into account enterprises that function without innovations and don't have enough ability and economic possibilities for realizing the full complex of functions, further studies may be devoted to searching for instruments of the operational development of such enterprises too.

\section{References}

[1] Haapasalo, H., Ingalsuo, K., Lenkkeri, T. (2006). Linking strategy into operational management. Benchmarking: An International Journal, 13 (6), 701-717. doi: http://doi.org/10.1108/14635770610709068

[2] Vasenev, K. P. (2017). Construction of integrated planning system for an industrial enterprise in a turbulent market environment. Bulletin of the Moscow University. Series 6: Economic 4, 118-141.

[3] Kittsmann, H., Falko, S. G. (2017). Flexibility management of enterprise on the operational. Innovatsiyi v menedzhmenti, 11, 26-31.

[4] Belokon, A. M. (2011). Building a system of strategy-oriented operational management. Electronic Journal «Trudy MAI», 46. Available at: http://trudymai.ru/upload/iblock/b3a/postroenie-sistemyoperativnogo-upravleniya_-orientirovannogo-na-strategiyu.pdf

[5] Yakovleva-Chernysheva, A. Y. (2015). Theoretical aspects of the management of sustainable development of entrepreneurial organizations. Gumanizatsiya obrazovaniya, 1, 56-62.

[6] Marshall, A. (1993). Principles of economic science. Vol. 1. Moscow: Publishing group «Progress», 326.

[7] Foss, N. J. (1994). The theory of the firm: The Austrians as precursors and critics of contemporary theory. The Review of Austrian Economics, 7 (1), 31-65. doi: http://doi.org/10.1007/bf01102135

[8] Casson, M. C.; Foss, N., Mahnke, V. (Eds.) (2000). An Entrepreneurial Theory of the Firm. Competence, Governance and Entrepreneurship: Advances in Economic Strategy Research. Oxford: Oxford University Press, 116-145.

[9] Pobol, A. I. (2007). The theoretical roots of the concept of science-intensive entrepreneurship. Works of the Minsk Institute of Management and Entrepreneurship, 3 (11), 106-112.

[10] Teece, D. J. (2018). Business models and dynamic capabilities. Long Range Planning, 51 (1), 40-49. doi: http://doi.org/10.1016/j.lrp.2017.06.007

[11] Prykhozhay, V. (2011). Dynamic systems and their properties. LibTime. Available at: https:// libtime.ru/modelirovanie/dinamicheskie-sistemy-i-ih-svoystva.html

[12] Alyokhin, A. B. (2017). Category of development in strategic planning of industrial enterprises in the ligth of the logical approach. Herald of Khmelnytskyi national university, 4, 14-20. 